\title{
Use of genotyping based clustering to quantify recent tuberculosis transmission in Guadeloupe during a seven years period: analysis of risk factors and access to health care
}

Séverine Ferdinand ${ }^{1}$, Julie Millet ${ }^{2}$, Annick Accipe ${ }^{3}$, Sylvie Cassadou ${ }^{4}$, Pascal Chaud ${ }^{5}$, Maryse Levy ${ }^{3}$, Max Théodore ${ }^{1,3}$ and Nalin Rastogi ${ }^{2^{*}}$

\begin{abstract}
Background: The present study aimed to characterize Mycobacterium tuberculosis population structure and to identify transmission chains and risk factors by prospective molecular typing in conjunction with conventional epidemiological investigations in the French overseas department of Guadeloupe.

Methods: The study included all the culture-positive TB cases (1 clinical isolate per patient; $n=129$ ) diagnosed between a seven year period (April $4^{\text {th }}, 1999$ to December $31^{\text {st }}, 2005$ ). Prospective molecular typing was performed using spoligotyping and VNTRs, and a subset of $44 \mathrm{M}$. tuberculosis isolates found to be clustered was retrospectively typed using 12-loci MIRUs. Data were compared using the SITVIT2 database, followed by analysis of risk factors in function of clustering of the isolates and available demographic and socioeconomic data.

Results: The study sample was characterized by a majority of new cases (87.4\%); a moderate proportion of drugresistance (7.8\%); a high level of immigration (51.2\% foreign-born) originating from high TB/HIV incidence neighboring islands such as Haiti or Dominican Republic; lower socioeconomic conditions (70.7\% of jobless, average income $824 \mathrm{EUR} /$ month); and a significantly higher proportion of TB/HIV co-infected cases (38.2\% vs. 8.5\%; $p<0.001)$, and extrapulmonary disease $(18.2 \%$ vs. $4.8 \% ; p<0.02)$ among migrants as compared to French patients. The study revealed an important delay in access to healthcare with a median delay of 74.5 days between the 1st symptoms and clinical suspicion of TB. Prospective molecular typing based on spoligotyping and 5-loci VNTRs showed that evolutionary recent Euro-American lineages predominated in Guadeloupe (91.5\% of isolates). In conjunction with epidemiological data, it allowed to estimate a recent transmission rate of $18.6 \%$, which was close to the rate of $16.7 \%$ estimated using retrospective 12-loci MIRU typing. Although a higher proportion of cases in older age-group were apparently linked to reactivation; univariate analysis of risk factors did not allow pinpointing specific risk factors for a patient to belong to a TB transmission group.

Conclusions: Ongoing TB transmission in the insular, low TB-incidence setting of Guadeloupe can be defined as follows: (i) a significant proportion of imported cases of the disease from neighboring islands; (ii) significantly higher TB/HIV coinfection among foreign-born cases; and, (iii) a higher proportion of cases affecting older age-group among French patients due to reactivation. This study emphasizes the need for universal typing using spoligotyping and 15-loci MIRUs in prospective studies.
\end{abstract}

Keywords: Mycobacterium, Tuberculosis, Transmission, Guadeloupe, Genotyping, Spoligotyping, Exact-TandemRepeats, Database, Drug-resistance

\footnotetext{
* Correspondence: nrastogi@pasteur-guadeloupe.fr

${ }^{2}$ WHO Supranational TB Reference Laboratory, Institut Pasteur de la Guadeloupe, Abymes, Guadeloupe, France

Full list of author information is available at the end of the article
} 


\section{Background}

There has been major progress in reducing tuberculosis (TB) cases in the past two decades, yet the global burden of TB remains enormous. The World Health Organization (WHO) estimated that there were 8.7 million incident cases of TB and 1.4 million deaths in 2011 [1]; HIV pandemic apparently played a major role in it, since $13 \%$ of the TB patients were co-infected with HIV and accounted for $30.7 \%$ of all deaths due to TB. Even if most of the TB cases occurred in Asia (59\%) and Africa $(26 \%)$, a non negligible proportion was reported in the Eastern Mediterranean (7\%) and European (5\%) regions, followed by the Americas (3\%). To achieve the current goal of a high level of case detection (75\%) and cure (85\%) by the year 2015 , a finer study of the epidemiological characteristics of TB patients to pinpoint risk factors involved and access to health care is needed in different regions of the world [2]. Molecular fingerprinting of Mycobacterium tuberculosis has been proposed as an ideal investigational strategy to achieve this objective, since it allows to incorporate genotyping based clustering to quantify recent $\mathrm{TB}$ transmission in order to analyze risk factors and access to health care [3-5]. We hereby report results of such an investigational approach under a prospective genotyping study covering TB transmission during a 7 year period (1999-2005) in Guadeloupe, a French overseas department of the Americas. Under this study, all the $M$. tuberculosis strains were characterized by spoligotyping [6] and Variable Number of Tandem DNA Repeats (VNTRs; [7]) that were methods of choice when this investigation was planned back in 1998, with the aim of determining potential transmission links between TB patients. This prospective study also undertook concomitant investigations to study the access to health care and follow-up of the TB patients diagnosed.

\section{Methods}

Study design, patients, and $M$. tuberculosis isolates

After a prior explanation of the recommended investigations for the diagnostic purposes by a physician, patients were asked to sign an agreement letter and the pathological specimens were obtained from suspected tuberculosis patients. Only patients residing in Guadeloupe for more than three months were eligible. The cultures were performed using Löwenstein-Jensen slants at $37^{\circ} \mathrm{C}$, and were duly identified as $M$. tuberculosis complex using classical biochemical tests and the AccuProbe test (GenProbe Inc., San Diego, CA). All positive cultures were also subjected to drug-susceptibility testing using the proportional method on Löwenstein-Jensen media. The study performed between April $4^{\text {th }}, 1999$ and December $31^{\text {st }}$, 2005 corresponded to a recruitment of 129 TB patients with one $M$. tuberculosis clinical isolate per patient. For each patient, the data requested included nature of pathological specimen, result of AFB smear, the date of diagnosis, the clinical form of the disease, results of HIV serology, and previous history of TB. Demographic and socioeconomic data as well as information relating to the diagnosis were collected by the investigator after individually interviewing each patient using a specific form.

\section{Ethical considerations}

The study protocol was presented to the Conseil National de l'Ordre des Médecins (http://www.conseilnational.medecin.fr/qu-est-ce-que-l-ordre-1206), which guarantees the quality of healthcare provided to the patients. As recommended, it was thereafter submitted to the Commission nationale de l'informatique et des libertés (CNIL; http://www.cnil.fr/english/the-cnil/operation/\#c1556) which ensures the protection of personal data. Patients were duly informed about the description and aims of the study in writing, and those enrolled after their oral consent were asked to sign an agreement letter, returned to investigators. The study was approved by CNIL under a formal agreement number 999343 (modalities of registration, storage and analysis of epidemiological, clinical and socioeconomic data are available online from: www.pasteur-guadeloupe.fr/tb/projects/tuberculose.pdf).

\section{Molecular typing}

Right from the beginning of the prospective study in 1999, the molecular typing was planned using two PCRbased systems - spoligotyping [6] and VNTRs [7], since this typing scheme is significantly cheaper and faster than the historical "gold standard" IS6110-RFLP that was used for earlier M. tuberculosis genotyping work in Guadeloupe [8-10]; yet provided with results that were relevant for epidemiological investigations around clustered cases of TB [11]. Briefly, the genomic bacterial DNA was prepared by the cetyltrimethylammonium bromide (CTAB) method [12] from cultured strains. Spoligotyping using primers designated DRa and DRb (with DRa biotinylated at 5') to amplify the whole Direct Repeat (DR) region was performed as described previously [6]. As spoligotyping used alone may overestimate the number of potentially linked isolates, it was used in association with VNTR typing using exact tandem repeats ETR-A to ETR-E as a $2^{\text {nd }}$-line VNTR typing method as reported [7].

After the completion of the study, a subset of $44 M$. tuberculosis isolates found to be clustered by combination of spoligotyping and 5-loci VNTRs was retrospectively typed by using the 12-loci MIRU-VNTRs system described later [13]; since it allows a better discrimination than the 5-loci VNTRs that were available when 
the prospective study was planned back in 1998. The PCR-based 12-loci MIRU-VNTR typing was performed using primers described previously $[13,14]$, and the presence and size of each PCR product was determined manually by electrophoresis on an agarose gel, followed by staining with ethidium bromide as reported previously [15]. Note that although theoretically ETR-D and E correspond to MIRU locus 4 and 31, the primers and calculations based on ETR determination according to the protocols of Frothingham and Meeker-O'Connell [7] versus Supply et al. $[13,14]$, might not turn up in identical copy number for ETR-D and MIRU-4.

\section{Genotype analysis, database comparison, and recent transmission rate}

Spoligotype patterns as octal codes, 5-loci VNTRs, and 12-loci MIRU-VNTR data were entered in the SITVIT2 proprietary database of the Institut Pasteur de la Guadeloupe, which is an updated in-house version of the publicly released SpolDB4 [16] and SITVITWEB [17] databases. In this database, Spoligotype International Type (SIT), VNTR International Type (VIT), and MIRU International Type (MIT) designate identical patterns shared by 2 or more patient isolates, whereas "orphan" designates patterns reported for a single isolate that does not correspond to any of the patterns recorded in the repository of the SITVIT2 database. Major phylogenetic clades were assigned according to signatures initially provided in SpolDB4, and slightly revised in SITVITWEB by the addition of 5 "new rules" for definition of variants within 62 existing lineages/sub-lineages. These include specific signatures for various $M$. tuberculosis complex members, as well as rules defining major lineages/sub-lineages for $M$. tuberculosis stricto sensu, i.e., the Beijing clade, the Central Asian (CAS) clade and two sublineages, the East African-Indian (EAI) clade and nine sublineages, the Haarlem $(\mathrm{H})$ clade and three sublineages, the Latin American-Mediterranean (LAM) clade and 12 sublineages, the "Manu" family and three sublineages, the S clade, the IS6110-low-banding X clade and four sublineages, and an ill-defined $\mathrm{T}$ clade with five sublineages. Lastly, the recent transmission rate was estimated by the N-1 method [5], according to formula $\mathrm{T}(\mathrm{c})-\mathrm{N}(\mathrm{c}) / \mathrm{T}(\mathrm{a})$, where $\mathrm{T}(\mathrm{c})$ is the total number of clustered isolates, $\mathrm{N}(\mathrm{c})$ is the number of clusters, and $\mathrm{T}$ (a) is the total number of isolates.

\section{Epidemiological, phylogenetical, and statistical analysis}

Epidemiological and demographic data collected were analyzed using Epi-Info 3.2.2 software (Centers for Disease Control and Prevention, Atlanta, GA; free download available at http://www.cdc.gov/epiinfo). The statistical analysis was carried out with STATA 9.0 software (StataCorp, College Station, TX). Patients were divided into 2 groups: clustered patients (infected by strains harboring identical genotypic patterns), versus unclustered patients. The Chi-2, Fischer exact, and Student tests (according to the variables considered) were carried out using univariate analysis in order to test risk factors in function with clustering of the isolates. Odds ratio were calculated with a confidence interval of $95 \%$. A qualitative analysis of the data collected was performed to evaluate the possible ways of infection. The phylogenetical analysis of genotyping data was carried out using "PAUP 4.0" software (available at: http:// paup.csit.fsu.edu) and UPGMA (Unweighted Pair Group Method with Arithmetic Averages) algorithm on combined genotyping data.

\section{Results}

Demographic characteristics, geographic localization, and drug resistance

Epidemiological and demographic data of the 129 patients with a culture-positive, confirmed $M$. tuberculosis infection are summarized in Table 1. The population of TB patients in Guadeloupe is characterized by a male to female sex-ratio of 1.5 with a median age of patients of 40 years. Overall TB principally affected men in the age group $40-59$ years $(n=32 / 77$ or $41.6 \%$ of all male patients); male patients being older than females (median age of 42 vs. 36 years). More than 1 out of 2 patients was foreign-born (63/129 or $48.8 \%$ French vs. $66 / 129$ or $51.2 \%$ foreign-born), who had been residing in Guadeloupe for approximately 10 years at the time of diagnostic. The exact place of birth was available for 126/129 patients: 53/126 (42.1\%) were born in Haiti, 5/ 126 (4\%) in Dominican Republic and 52/126 (41.3\%) in French overseas departments (Guadeloupe $n=43$, Martinique $n=1$, French Guiana $n=1$ ), or other departments in continental France $(n=7)$. Foreign-born patients were significantly younger (median age 36 years vs. 50 years for French patients; $p<0.001$ ); the proportion of patients below 60 years being 63/66 or 95.5\% among foreign-born vs. $40 / 63$ or $63.5 \%$ for French patients $(p<0.001)$. Lastly, men were older than females among the foreign-born group: 39 vs. 34 years as compared to 49 vs. 58 years for French nationals (difference not significant statistically). These results corroborate published data from mainland France for French vs. foreign-born patients for the year 2004 [18]. Geographic localization of patients showed that 27/34 cities of Guadeloupe archipelago (including its island dependencies of Saint-Martin, Saint-Barthelemy, Marie-Galante, Desirade, and Les Saintes) declared at least one case of tuberculosis during the period of the study; 6 areas shared 69/116 (59.5\%) of the TB cases for which this information was available: Saint-Martin 20/116 (17.2\%); Les Abymes 20/116 (17.2\%); Le Gosier, 10/116 (8.6\%); 
Table 1 Demographical and epidemiological data of the 129 tuberculosis patients from Guadeloupe in function of their place of birth

\begin{tabular}{|c|c|c|c|c|c|}
\hline \multicolumn{2}{|c|}{ Parameters studied } & \multirow{2}{*}{$\begin{array}{l}\text { Total number } \\
(\%)(n=129)\end{array}$} & \multirow{2}{*}{$\begin{array}{l}\text { Foreign-born patients number } \\
\qquad(\%)(n=66)\end{array}$} & \multirow{2}{*}{$\begin{array}{l}\text { French patients number } \\
(\%)(n=63)\end{array}$} & \multirow[t]{2}{*}{$p$} \\
\hline Sex & & & & & \\
\hline & male & 77 (59.7) & $35(53.0)$ & $42(66.7)$ & NS \\
\hline & female & $52(40.3)$ & $31(47.0)$ & $21(33.3)$ & \\
\hline & unknown & 0 & 0 & 0 & \\
\hline \multicolumn{6}{|c|}{ Age group } \\
\hline & $0-14$ years & $1(0.8)$ & $1(1.5)$ & $0(0)$ & $<0.001$ \\
\hline & $15-24$ years & $12(9.3)$ & $10(15.2)$ & $2(3.2)$ & \\
\hline & $25-39$ years & $44(34.1)$ & $26(39.4)$ & $18(28.6)$ & \\
\hline & $40-59$ years & $46(35.7)$ & $26(39.4)$ & $20(31.7)$ & \\
\hline & $>60$ years & $26(20.2)$ & $3(4.5)$ & $23(36.5)$ & \\
\hline & unknown & 0 & 0 & 0 & \\
\hline \multicolumn{6}{|c|}{ Employment $^{\mathrm{a}}$} \\
\hline & no & $65(70.7)$ & $37(72.5)$ & $28(68.3)$ & NS \\
\hline & yes & $27(29.3)$ & $14(27.5)$ & $13(31.7)$ & \\
\hline & unknown & 37 & 15 & 22 & \\
\hline \multicolumn{6}{|c|}{ Positive HIV status } \\
\hline & no & $77(75.7)$ & $34(61.8)$ & $43(91.5)$ & $<0.001$ \\
\hline & yes & $25(24.5)$ & $21(38.2)$ & $4(8.5)$ & \\
\hline & unknown & 27 & 11 & 16 & \\
\hline \multicolumn{6}{|c|}{ Smoker } \\
\hline & no & $76(80.0)$ & 45 (83.3) & $31(75.6)$ & NS \\
\hline & yes & $19(20.0)$ & $9(16.7)$ & $10(24.4)$ & \\
\hline & unknown & 34 & 12 & 22 & \\
\hline \multicolumn{6}{|c|}{ Excessive alcohol user ${ }^{b}$} \\
\hline & no & $69(71.9)$ & $47(85.5)$ & $22(53.7)$ & $<0.001$ \\
\hline & yes & $27(28.1)$ & $8(14.5)$ & $19(46.3)$ & \\
\hline & unknown & 33 & 11 & 22 & \\
\hline \multicolumn{6}{|c|}{ Drug user } \\
\hline & no & $81(87.1)$ & $50(96.2)$ & $31(75.6)$ & $<0.01$ \\
\hline & yes & $12(12.9)$ & $2(3.8)$ & $10(24.4)$ & \\
\hline & unknown & 36 & 14 & 22 & \\
\hline \multicolumn{6}{|c|}{ Prior history of active TB } \\
\hline & no & $90(87.4)$ & $53(93.0)$ & $37(80.4)$ & NS \\
\hline & yes & $13(12.6)$ & $4(7.0)$ & $9(19.6)$ & \\
\hline & unknown & 26 & 9 & 17 & \\
\hline \multicolumn{6}{|c|}{ Sputum AFB smear result } \\
\hline & no & $38(29.5)$ & $21(31.8)$ & $17(27.0)$ & NS \\
\hline & yes & $91(70.5)$ & $45(68.2)$ & $46(73.0)$ & \\
\hline & unknown & 0 & 0 & 0 & \\
\hline
\end{tabular}


Table 1 Demographical and epidemiological data of the 129 tuberculosis patients from Guadeloupe in function of their place of birth (Continued)

\begin{tabular}{|c|c|c|c|c|c|}
\hline \multicolumn{6}{|l|}{ Drug resistance } \\
\hline & no & $119(92.2)$ & $61(92.4)$ & $58(92.1)$ & \multirow[t]{3}{*}{ NS } \\
\hline & yes & $10(7.8)$ & $5(7.6)$ & $5(7.9)$ & \\
\hline & unknown & 0 & 0 & 0 & \\
\hline \multicolumn{6}{|l|}{ Localization of TB ${ }^{\mathrm{C}}$} \\
\hline & pulmonary & $114(88.4)$ & $54(81.8)$ & $60(95.2)$ & \multirow[t]{3}{*}{$<0.02$} \\
\hline & extrapulmonary & $15(11.6)$ & $12(18.2)$ & $3(4.8)$ & \\
\hline & unknown & 0 & 0 & 0 & \\
\hline \multicolumn{6}{|c|}{ Treatment outcome $^{d}$} \\
\hline & completed treatment / cured & $63(55.8)$ & $37(66.1)$ & $26(45.6)$ & \multirow[t]{4}{*}{ NS } \\
\hline & died before treatment completed & $17(15.0)$ & $6(10.7)$ & $11(19.3)$ & \\
\hline & lost to follow up & $33(29.2)$ & $13(23.2)$ & $20(35.1)$ & \\
\hline & unknown & 16 & 10 & 6 & \\
\hline
\end{tabular}

a Employment: the "yes" includes patients who answered positively to the question "Do you currently have a regular professional activity?"

b Excessive alcohol user: "yes" concerns patients drinking more than 4 glasses of alcoholic beverages per day.

' Localization of TB: Pulmonary, patients without any extrapulmonary manifestation of TB; Extrapulmonary, patients with extrapulmonary or disseminated TB, as well as with combined manifestations of extrapulmonary and pulmonary TB.

d Treatment outcome: "completed treatment" includes only cured patients.

Abbreviations: NA Not Applicable, NS Non Significant (significance level below 0.05).

Pointe-à-Pitre, 8/116 (7.0\%); Baillif, 6/116 (5.2\%); and Basse-Terre, 5/116 (4.3\%). Regarding drug resistance, $10 / 129(7.8 \%)$ cases were associated to any drug resistance; cumulative resistance to isoniazid and rifampicin (multidrug resistance or MDR) concerned 3/129 (2.3\%) cases.

\section{Access to healthcare and delay to diagnosis}

Access to healthcare was defined as the delay comprised between the first symptoms of $\mathrm{TB}$ and the date of its clinical suspicion. This interval includes 2 periods: the access time to $1^{\text {st }}$ medical contact which is the delay comprised between the $1^{\text {st }}$ symptoms of TB and the date of $1^{\text {st }}$ medical contact for those symptoms, and the time of clinical suspicion defined as the delay extending from the date of $1^{\text {st }}$ medical contact to the date of clinical suspicion of TB. In the present study, the median access time to $1^{\text {st }}$ medical contact and to clinical suspicion were equal to 16 and 26.5 days respectively leading to a median delay to healthcare of 74.5 days. We observed that patients treated after clinical suspicion presented a significantly longer median delay of access to healthcare than those treated after bacteriological investigations (median delay of 80 vs. 37 days respectively; $p<0.017$ ); due to a longer access time to $1^{\text {st }}$ medical contact (median delay of 19 vs. 8 days respectively) and a significantly longer delay of clinical suspicion $(33.5 \mathrm{vs}$. 10.5 days respectively; $p<0.03$ ). Remarkably, in both groups of patients, the diagnostic delay was longer than the access time to the first medical contact. The primary reason for consulting a physician for a first medical contact was persistent cough with fever (median 16 days). $\mathrm{TB}$ was suspected at the $1^{\text {st }}$ medical contact for $69 / 107$ $(64.5 \%)$ patients, $2^{\text {nd }}$ contact for $22 / 107$ (20.6\%), patients, $3^{\text {rd }}$ contact for $10 / 107(9.3 \%)$ patients, and later for 6/107 (5.6\%) patients. Patients for whom a presumptive diagnosis of TB was made at the 1st medical contact had a longer delay in consulting the physician after the onset of clinical symptoms (30.5 vs. 3.5 days for other patients; $p<0.0001$ ). Nonetheless, these were diagnosed for TB significantly faster than the remaining patients (10.5 vs. 74 days; $p=0.025$ ) most probably due to a more advanced state of the disease; which suggests that efforts targeting early medical diagnosis of $\mathrm{TB}$ must be intensified.

\section{Socioeconomic characteristics}

As summarized in Table 1, only 27/92 (29.3\%) patients had a regular work (employees $n=13$, workmen $n=4$, farmers $\mathrm{n}=4$, craftsmen $\mathrm{n}=3$, management $\mathrm{n}=2$, and unspecified job $\mathrm{n}=1)$. The remaining 65/92 $(70.7 \%)$ patients were jobless, nonetheless 19/65 (29.2\%) reported doing small undeclared jobs from time to time. Overall, the TB patients constituted a low income group with an average earning of 824 EUR/month (range, 40 - 5000 EUR). The underprivileged nature of the TB patient group was also reflected by the fact that $18.9 \%$ shared a single room with 2 or more persons, and $52.2 \%$ used regularly public transport. Regarding addiction, 27/96 (28.1\%) were regular alcohol consumers (more than 4 glasses of alcoholic beverages/day), and 19/95 (20.0\%) were smokers among whom 10/19 (52.6\%) smoked more than a packet of 20 cigarettes/day. Drug consumption 
was known for 93 patients, and 12/93 (12.9\%) declared consuming cannabis and/or crack regularly. Lastly, only 10/91 (11\%) patients affirmed having frequent relation to public, although 53/91 patients (58.2\%) attended church regularly. During the 2 years preceding the diagnosis of TB, 17/89 (19.1\%) patients had carried out 21 trips in 14 French departments (11 French and 6 foreign-born). In general, the French nationals mostly traveled to mainland France (10/ $11)$, as opposed to foreign-born patients who traveled within the French departments of Americas (4/6). Despite the highly precarious living conditions of the patient group, 27/ $89(30.3 \%)$ patients also carried out 42 international travels in 12 countries (mostly to neighboring Caribbean countries). These trips outside the French overseas departments essentially concerned foreign-born patients returning to their homeland, the highest proportion being made up of Haitians $(\mathrm{n}=16)$.

\section{Clinical characteristics and treatment outcome}

Table 1 also describes clinical characteristics of the 129 patients of the study. Data collected showed that extrapulmonary TB was more frequent among the foreignborn group of patients as compared to French nationals $(12 / 66$ or $18.2 \%$ vs. $3 / 63$ or $4.8 \%$; $p<0.02)$. Previous history of TB was known for 103/129 patients; 90 were new cases (87.4\%) while 13 patients (14.4\%) were previously treated for TB (8 pulmonary, 1 extrapulmonary, 1 pulmonary case associated with a genital form, 3 unknown). Underlying medical conditions were known for 92/129 patients, and revealed that $38.0 \%$ (35/92) of the patients were also simultaneously treated for associated diseases (diabetes, prostate cancer, liver cancer, arterial hypertension, asthma). HIV serology was known for 102/129 patients (55 foreign-born and 47 French nationals) with a global TB/HIV co-infection rate of $24.5 \%$ (25/102); the latter was significantly higher among foreign-born group (21/55 or $38.2 \%$ vs. $4 / 47$ or $8.5 \%$ for French nationals; $p=0.001$ ). This co-infection rate of $24.5 \%$ places Guadeloupe largely ahead of metropolitan France with $10 \%$ of TB/HIV co-infection for the same time period [19].

Treatment outcome was known for 113/129 patients; 63/113 (55.8\%) were cured, 33/113 (29.2\%) were lost to follow-up, and 17/113 (15\%) died within 4 months after the diagnostic of $\mathrm{TB}$, mostly due to underlying health conditions (Table 1). Among those lost of sight $(\mathrm{n}=33)$, 26 patients followed their initial treatment for an unspecified period of time (median delay of 4 months after the initial phase of treatment in hospital, no information available for 7 patients).

\section{Genotyping, clustering, and phylogenetical analysis}

Spoligotyping of the 129 clinical isolates generated 57 different patterns presented in Figure 1 and Additional file 1: Table S1, among which 49 profiles were already present in our database with a SIT number, 3 profiles matched orphan patterns in the database creating new shared-types (SITs 1913, 2383, and 2689), and 5 were not reported earlier and labeled as orphan. A total of 90/ $129(69.8 \%)$ isolates were grouped into 18 clusters (2 to 12 strains per cluster) while 39/129 (30.2\%) were unique in this study. The overall lineage distribution was as follows: LAM ( $\mathrm{n}=38 / 129$ or $29.5 \%)$, ill-defined T family $(n=39 / 129$ or $30.2 \%)$, Haarlem $(n=30 / 129$ or $23.3 \%), X$ clade $(\mathrm{n}=8 / 129$ or $6.2 \%)$, $\mathrm{S}$ family $(\mathrm{n}=3 / 129$ or $2.3 \%)$, EAI ( $n=2 / 129$ or $1.6 \%)$, and AFRI ( $n=1 / 129$ or $0.8 \%)$.

We also looked in the updated version of the SITVIT2 database for the geographical distribution of all clustered isolates found in Guadeloupe vs. their relative distribution in all the 3 French Departments of the Americas (Guadeloupe, Martinique, and French Guiana), Caribbean, South and central America, as well as the remaining countries worldwide (database interrogation made on April $25^{\text {th }}$ 2013; Table 2). One can observe essentially 5 kinds of situations: (i) ubiquitous spoligotypes present in a very high proportion in the database (SIT42/LAM9, SIT50/H3, SIT53/T1), (ii) patterns that are shared between the 3 French departments, Caribbean, South and Central America and the rest of the world, although in varying proportions $(\mathrm{SIT} 2 / \mathrm{H} 2$, SIT3/H3, SIT7/T1, SIT20/ LAM1, SIT44/T5, SIT45/H1, SIT51/T1, SIT93/LAM5, SIT122/T1), (iii) patterns with a phylogeographical specificity for South and Central America that are present in Caribbean including Guadeloupe (SIT17/LAM2); (iv) patterns that are shared between Caribbean and the rest of the world but absent in South and Central America (SIT5/T1, SIT70/X3); (v) patterns that show phylogeographical specificity for French Departments in general and Guadeloupe in particular (SIT14/X3, SIT103/H1, SIT1087/T1).

Genotyping of the 5-loci VNTRs provided complete and/or interpretable results for 116/129 strains (Figure 1) with 15 clusters ( $\mathrm{n}=106$ isolates, 2-27 strains/cluster). Note that 9 of the 10 unclustered strains (with the exception of pattern 96245) matched an existing VIT number in the database, and no VIT numbers were newly created due to a newly found pattern or a match with preexisting orphan in the database.

The combination of spoligotypes and VNTRs revealed 76 distinct profiles for the 129 isolates: 58 corresponded to unique vs. 18 for clustered strains $(\mathrm{n}=71,2-9$ isolates/cluster; labeled as A, B1, B2, C1, C2, C3, D, E, F, G1, G2, G3, G4, H, I1, I2, I3, and J in Figure 1). When epidemiological data were analyzed in combination with clustering, we observed that mean age of patients among the 18 clusters varied from 27 (cluster $\mathrm{I} 1, \mathrm{n}=2$ ) to 59 years old (cluster $\mathrm{G} 2, \mathrm{n}=3$ ), and that the male to female sex ratio varied from 0 (cluster $E, n=2$ ) to 3 (cluster A, $\mathrm{n}=4$ ); with 4 clusters composed exclusively of 


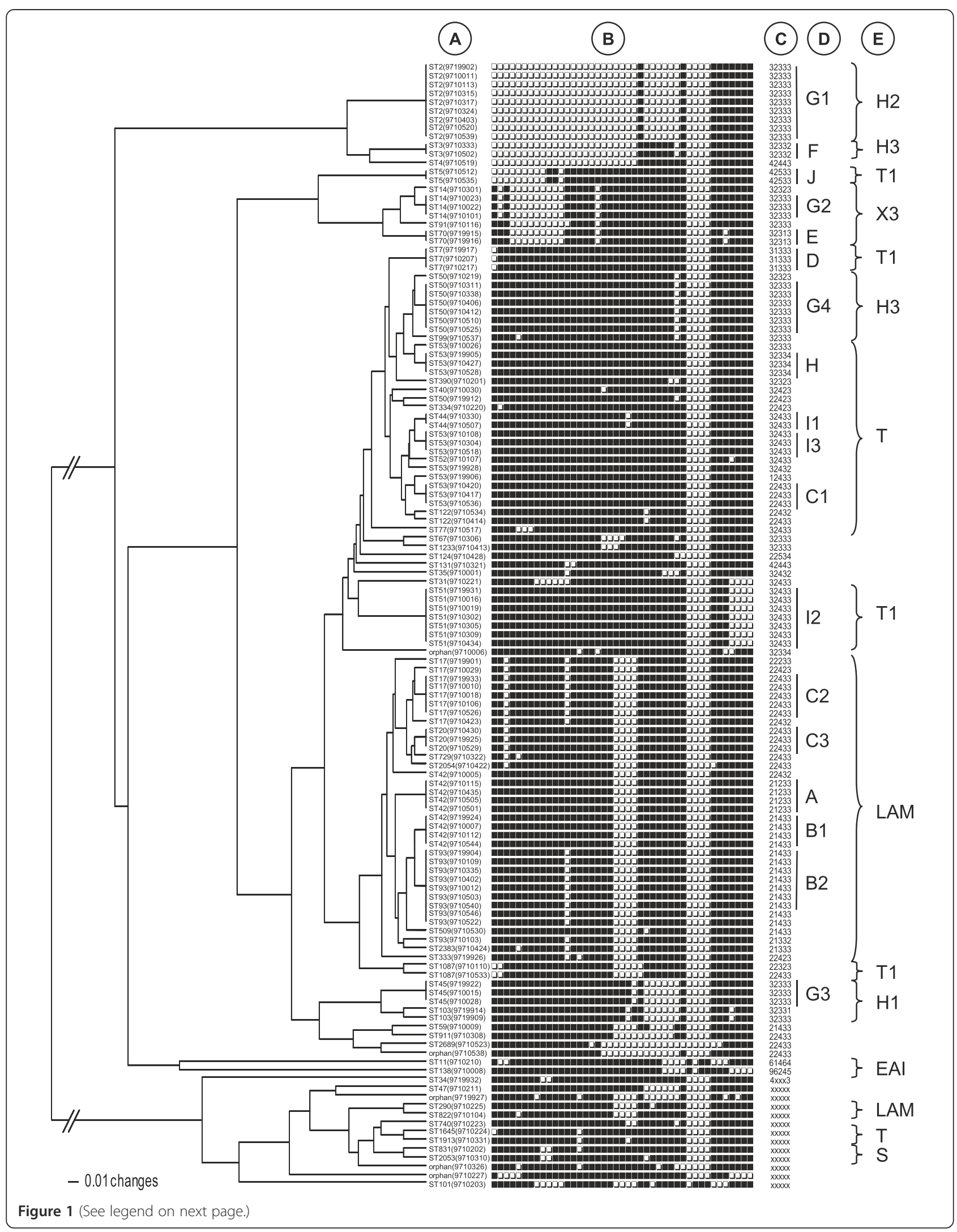


(See figure on previous page.)

Figure 1 UPGMA dendrogram obtained through a combined numerical analysis of spoligotypes and VNTR profiles of the $129 \mathrm{M}$.

tuberculosis clinical isolates from Guadeloupe. The letters in front of the tree correspond to the following information: A: SIT numbers of the spoligotype profiles with, in brackets, the strain numbers; B: binary spoligotypes; C: 5-loci VNTR profiles. The " $x$ " symbol among a profile indicates a missing or uninterpretable result; $\mathbf{D}$ : clusters numbers; $\mathbf{E}$ : clades attribution of the spoligotype profiles.

male patients (clusters C1 $\mathrm{n}=3$; D $\mathrm{n}=3$; $\mathrm{G} 2 \mathrm{n}=3$; J $\mathrm{n}=$ 2). Regarding drug resistance, 3 clusters contained 1 MDR strain each (clusters J, C2, and B2; the MDR strain of $\mathrm{C} 2$ was simultaneously resistant to INH, RIF, EMB while that of cluster J to INH, RIF, EMB, SM). Furthermore, 1 cluster contained 2 monoresistant strains (to SM and INH, cluster G4); while 2 others contained 1 monoresistant strain each to INH (cluster C3) and to SM (cluster $\mathrm{H}$ ).

It should be underlined that the cluster I1 composed of the youngest patients, did not contain any drug resistant strains, and that the 3 patients infected with MDR strains were simultaneously HIV-positive. A comparison with the SITVIT2 database showed that the combined spoligotyping + 5-loci VNTR profiles of the 6 clusters including resistant strains, matched mainly strains from Haiti. For example, 9/10 strains in the database sharing cluster J pattern (SIT5/VIT193) were isolated from Haitian patients. Similarly, 14/16 patients with cluster B2 pattern (SIT93/VIT3); 20/24 strains with cluster C2 pattern (SIT17/VIT10), 26/36 strains with cluster C3 pattern (SIT20/VIT10), and 34/84 of strains with cluster G4 pattern (SIT50/VIT18), were also isolated from Haitian patients in the database. Unfortunately, drug resistance profiles were not systematically available in the database, making it impossible to definitely link the genotypes and drug resistance of isolates actively circulating between Haiti and Guadeloupe.

\section{Retrospective evaluation of clustered isolates by 12-loci MIRU typing}

Because during the time course of this 7 years prospective study, the TB molecular typing methodology evolved with the introduction of 12-loci MIRU typing [13,14], we decided to retrospectively genotype a subset of $44 \mathrm{M}$. tuberculosis strains clustered by the combination of spoligotyping and 5-loci VNTRs. The results obtained (Table 3) showed that 26/44 (59.1\%) strains remained clustered vs. $18 / 44$ (40.9\%) being unique by the combination of the 3 methods. This allowed decreasing the clustering rate and recent transmission rates in this subset from $55 \%$ and $41.1 \%$ respectively, to $25.5 \%$ and $16.7 \%$ respectively.

\section{Contact tracing investigations and risk factor analysis}

Rebuilding the ways of infection of TB cases due to a recent infection was carried out by cross analyzing genotyping data in conjunction with results of contact tracing investigations, as well as data collected through individual interviews. Contact tracing alone suggested a potential common source of infection for 6 patients of the study, which in our opinion is underestimated since only $54 \%$ of the TB cases diagnosed could be effectively covered by investigations among patient's entourage. Genotyping results combined with epidemiologic investigations underlined $23 \mathrm{~TB}$ cases categorized as recent transmission. Finally, the consideration of all the 3 parameters confirmed active transmission of TB for 24/129 (18.6\%) of cases.

A Univariate analysis of risk factors was performed in function to the clustering of $M$. tuberculosis isolates and available demographic, epidemiologic, clinical, and socioeconomic data. However, the results summarized in Table 4 showed that none of the risk factors tested could be significantly associated with active transmission of TB. Only the factor "age of patients below 60 years" was close to the statistical limit of significance $(p=0.06)$.

\section{Discussion}

This study is the first prospective epidemiological and molecular study of TB transmission in the French overseas department of Guadeloupe. When compared to TB epidemiology in mainland France, the most striking difference was the significantly higher proportion of TB/ HIV co-infected patients in Guadeloupe (24.5\% vs. $10 \%$ respectively; [19]). However, an almost similar proportion of drug-resistance and TB incidence were observed in 2005: the proportion of drug resistant isolates being $7.8 \%$ vs. $8.8 \%$, respectively, in Guadeloupe and continental France [19], and an incidence of 8.1 vs. 8.9 cases per 100,000 inhabitants [20]. Similarly to mainland France, men represented around $60 \%$ of $\mathrm{TB}$ patients in Guadeloupe a trend accentuated for the age group 4060 years in mainland France (68\% of TB patients) and 40-59 years in Guadeloupe (71.1\% of TB patients [20]). Lastly, TB in Guadeloupe was characterized by immigration with $51.2 \%$ of foreign-born patients in our study, which is slightly higher than $48 \%$ in mainland France in 2005 , but significantly lower than the $69 \%$ of foreign born patients observed in French Guyana (185/268; $p<0.001$; [20,21]). Immigrants in Guadeloupe mainly originated high TB incidence and AIDS burden surrounding Caribbean islands of Haiti and Dominican Republic, with reported TB incidence in 2005 of 305 and 
Table 2 Worldwide geographical distribution of major SITs found in Guadeloupe according to the SITVIT2 database (interrogation made on April 25 ${ }^{\text {th }}$, 2013)

\begin{tabular}{|c|c|c|c|c|c|c|c|c|c|}
\hline \multirow[b]{2}{*}{ SIT } & \multirow[b]{2}{*}{ Spoligotype description } & \multirow[b]{2}{*}{ Lineage } & \multirow{2}{*}{$\begin{array}{c}\text { Total } \\
\text { no. of } \\
\text { strains } \\
\text { (SITVIT2) }\end{array}$} & \multicolumn{6}{|c|}{ Geographical distribution $^{a}$} \\
\hline & & & & GLP & MTQ & GUF & Caribbean & South and Central America & $\begin{array}{l}\text { Other } \\
\text { countries }\end{array}$ \\
\hline 2 & | & $\mathrm{H} 2$ & 393 & 18 & 5 & 24 & 21(CUB), 37(HTI) & $\begin{array}{c}\text { 35(ARG), } 21(\mathrm{BRA}), 2 \text { 2(COL), 3(HND), 2(PAN), } 1 \\
\text { (PRY) }\end{array}$ & 224 \\
\hline 3 & 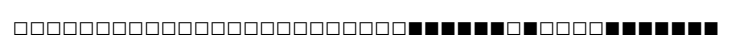 & H3 & 105 & 4 & 0 & 0 & 3(CUB), $1(\mathrm{HTI})$ & 2(ARG), 7(BRA), 3(COL), 1(SUR), 1 (VEN) & 83 \\
\hline 5 & Q & $\mathrm{T} 1$ & 30 & 3 & 2 & 4 & $7(\mathrm{HTI})$ & 0 & 14 \\
\hline 7 & 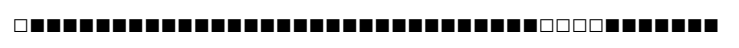 & T1 & 77 & 4 & 0 & 4 & 1(BHS), 2(HTI) & 1(PER), 2(PRY) & 63 \\
\hline 14 & ' & X3 & 42 & 27 & 6 & 2 & 0 & $1(\mathrm{VEN})$ & 6 \\
\hline 17 & 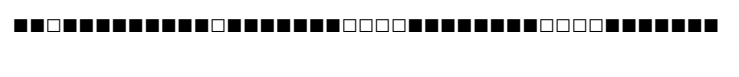 & LAM2 & 656 & 22 & 4 & 12 & $\begin{array}{c}1(\mathrm{CUB}), 9(\mathrm{DOM}), 22(\mathrm{HTI}), \\
1(\mathrm{TTO})\end{array}$ & $\begin{array}{c}\text { 2(ARG), 184(BRA), 13(COL), 1(PAN), 1(PER), } 1 \\
\text { (PRY), 179(VEN) }\end{array}$ & 204 \\
\hline 20 & 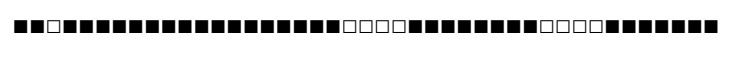 & LAM1 & 811 & 8 & 1 & 20 & 5(CUB), 26(HTI), 3(JAM) & $\begin{array}{c}\text { 2(ARG), 147(BRA), } 14(\mathrm{COL}), 5(\mathrm{PER}), 1(\mathrm{PRY}), 42 \\
\text { (VEN) }\end{array}$ & 537 \\
\hline 42 & 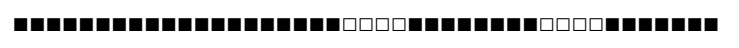 & LAM9 & 3282 & 24 & 8 & 31 & Ubiquitous & Ubiquitous & Ubiquitous \\
\hline 44 & 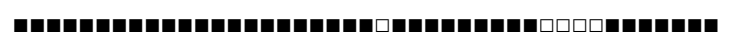 & T5 & 210 & 4 & 0 & 6 & 0 & 3(ARG), 3(BRA), 1(SUR), 4(VEN) & 189 \\
\hline 45 & 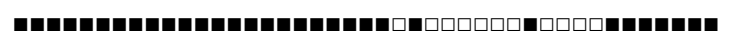 & $\mathrm{H} 1$ & 106 & 8 & 14 & 0 & 1(HTI), 3(LCA) & 9(BRA), 8(COL), 1 (PAN) & 62 \\
\hline 50 & 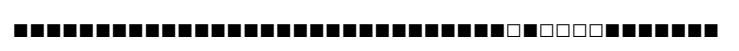 & H3 & 3330 & 23 & 16 & 88 & Ubiquitous & Ubiquitous & Ubiquitous \\
\hline 51 & 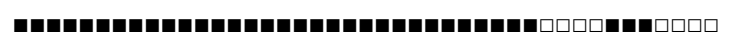 & $\mathrm{T} 1$ & 279 & 12 & 0 & 13 & 17(HTI), 3(JAM) & 4(ARG), 40(BRA), 1 (PER), 10(VEN) & 179 \\
\hline 53 & 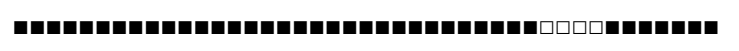 & $\mathrm{T} 1$ & 6104 & 39 & 25 & 84 & Ubiquitous & Ubiquitous & Ubiquitous \\
\hline 70 & 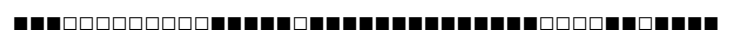 & X3 & 116 & 3 & 0 & 6 & 8(BHS), 8(HTI), 1(TTO) & 0 & 90 \\
\hline 93 & 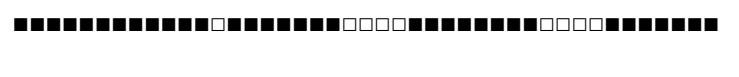 & LAM5 & 359 & 19 & 0 & 9 & 7(DOM), 15(HTI), 1 (TTO) & $\begin{array}{c}\text { 2(ARG), 43(BRA), 2(COL), } 17(\mathrm{PER}), 6(\mathrm{PRY}), 94 \\
\text { (VEN) }\end{array}$ & 144 \\
\hline 103 & 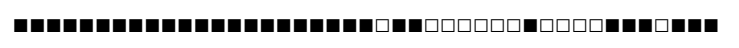 & $\mathrm{H} 1$ & 3 & 3 & 0 & 0 & 0 & 0 & 0 \\
\hline 122 & 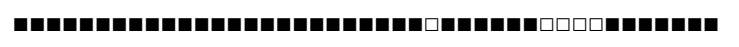 & $\mathrm{T} 1$ & 27 & 2 & 0 & 0 & 0 & 1(COL), 1(PAN) & 24 \\
\hline 1087 & 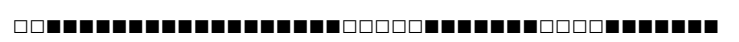 & $\mathrm{T} 1$ & 4 & 2 & 0 & 0 & $1(\mathrm{HTI})$ & 0 & 1 \\
\hline
\end{tabular}


Table 3 Retrospective 12-loci MIRU analysis of a subset of 44 M. tuberculosis strains initially clustered by using the combination of spoligotyping with 5-loci VNTRs

\begin{tabular}{|c|c|c|c|c|c|c|c|}
\hline Cluster & SIT & Spoligotype & VNTR & VIT & 12-loci MIRU & MIT & $\mathrm{Nb}$ of strains \\
\hline \multirow{2}{*}{$F(n=2)$} & \multirow{2}{*}{3} & \multirow{2}{*}{ | } & \multirow{2}{*}{32332} & \multirow{2}{*}{17} & 224313153223 & 181 & 1 \\
\hline & & & & & 225313153223 & 810 & 1 \\
\hline \multirow[t]{2}{*}{$J(n=2)$} & \multirow[t]{2}{*}{5} & \multirow[t]{2}{*}{ ' } & \multirow[t]{2}{*}{42533} & \multirow[t]{2}{*}{193} & 223325153322 & 15 & 2 \\
\hline & & & & & 224325133324 & 122 & 1 \\
\hline \multirow[t]{2}{*}{$\mathrm{G} 2(\mathrm{n}=3)$} & \multirow[t]{2}{*}{14} & \multirow[t]{2}{*}{ " } & \multirow[t]{2}{*}{32333} & \multirow[t]{2}{*}{18} & 224325133325 & 28 & 1 \\
\hline & & & & & 224325133326 & 1042 & 1 \\
\hline \multirow{2}{*}{$C 2(n=5)$} & \multirow{2}{*}{17} & \multirow{2}{*}{ ' } & \multirow{2}{*}{22433} & \multirow{2}{*}{10} & 224226163321 & 26 & 4 \\
\hline & & & & & Not Amplified & & 1 \\
\hline \multirow{2}{*}{$C 3(n=3)$} & \multirow{2}{*}{20} & \multirow{2}{*}{ 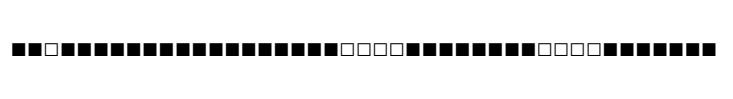 } & \multirow{2}{*}{22433} & \multirow{2}{*}{10} & 223226163321 & 307 & 2 \\
\hline & & & & & 223226193321 & 1048 & 1 \\
\hline \multirow{2}{*}{$A(n=4)$} & \multirow{2}{*}{42} & \multirow{2}{*}{ 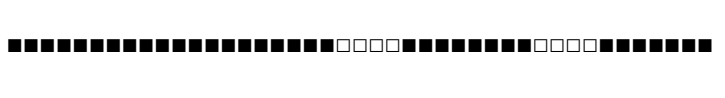 } & \multirow{2}{*}{21233} & \multirow{2}{*}{2} & 224226143321 & 738 & 1 \\
\hline & & & & & 224226153321 & 25 & 3 \\
\hline \multirow{2}{*}{ B1 $(n=4)$} & & & & & 224226153321 & 25 & 3 \\
\hline & 42 & 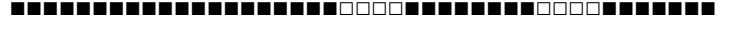 & 21433 & 3 & 233126142321 & 1539 & 1 \\
\hline $11(n=2)$ & 44 & 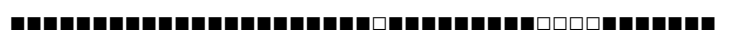 & 32433 & 23 & 223326153323 & 236 & 2 \\
\hline & & & & & 224325153321 & 161 & 1 \\
\hline$G 4(n-6)$ & 50 & 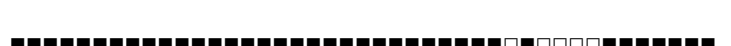 & 32333 & 18 & 225313153322 & 184 & 1 \\
\hline $34(11=0)$ & 50 & 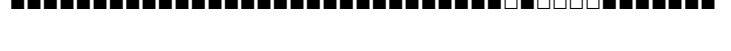 & 32333 & 10 & 225313153323 & 42 & 3 \\
\hline & & & & & 225323153323 & 43 & 1 \\
\hline & & & & & 227325163423 & 802 & 1 \\
\hline$H(n=3)$ & 53 & 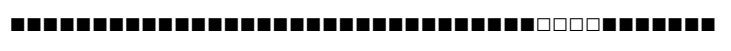 & 32334 & 19 & 228225163423 & 806 & 1 \\
\hline & & & & & 228325163423 & 415 & 1 \\
\hline & & & & & 222325153324 & 146 & 1 \\
\hline$C 1(n=3)$ & 53 & 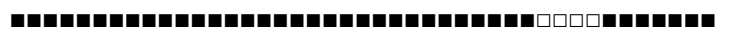 & 22433 & 10 & 223225153322 & 296 & 1 \\
\hline & & & & & 223425143322 & 160 & 1 \\
\hline B2 $(n=7)$ & 93 & 1010 & 21433 & 3 & 224226143321 & 738 & 2 \\
\hline $0<(11-7)$ & (5) & 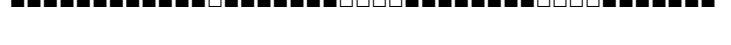 & 21435 & S & 224226153321 & 25 & 5 \\
\hline
\end{tabular}

91 cases/100 000 inhabitants [22], which might explain the relatively high rate of $\mathrm{TB} / \mathrm{HIV}$ coinfected patients among foreign born patients in our study $(38.2 \%$ vs. $8.5 \%$ for French patients; $p=0.001$ ).

The present study was meant to specifically evaluate the use of genotyping to quantify recent TB transmission with a focus on risk factors and access to health care during 1999-2005; and was followed by a study on evolution of TB cases during 2006-2011 [23]. We therefore attempted to compare TB evolution during these 2 time periods. As summarized in Table 5, one may notice a statistically significant decrease during the period 20062011 for 4 out of 9 parameters compared, namely, the proportion of foreign-born patients; patients lost of site; excessive alcohol users; drug addicts. The decrease in the proportion of foreign-born patients from $51.2 \%$ vs. $38.3 \%$ may be linked to the decrease in the proportion of migrants observed in Guadeloupe from $6.5 \%$ to $4.7 \%$ in
$2010[24,25]$. It may be noted that the decrease among lost of site is statistically significant both among foreignborn and French patients, while the decrease in excessive alcohol users and drug addicts was limited to French patients only. Regarding the 5 parameters that did not change significantly (Table 5), it might be worthwhile to comment on trends for TB/HIV coinfection which remained stable between the periods 1999-2005 and $2006-2011$ (24.5\% to 26.6\%), despite a slight but non-significant increase among both French-born $(8.5 \%$ to $13.9 \%)$ and foreign born patients (38.2\% vs. $46.9 \%)$. However, considering the reported decrease in the incidence of HIV/AIDS infection in Guadeloupe from 20 to 11.7 cases/100 000 inhabitant between 2003 and 2009 $[26,27]$, this observation might be explained on the basis of continued influx of a varying proportion of migrant workers from poor surrounding countries such as Haiti and Dominican Republic, where both TB and HIV/AIDS 
Table 4 Univariate analysis of risk factors in relation to the prospective genotype based clustering analysis of 129 M. tuberculosis isolates following spoligotyping and 5-loci VNTRs (clustered, $\mathbf{n}=71$ vs. unclustered, $\mathbf{n}=\mathbf{5 8}$ )

\begin{tabular}{|c|c|c|c|c|}
\hline \multirow[t]{2}{*}{ Risk factors } & \multicolumn{2}{|c|}{ No. of patients (\%) } & \multirow{2}{*}{$\begin{array}{l}\text { Odds ratio } \\
(95 \% \mathrm{Cl})\end{array}$} & \multirow[t]{2}{*}{$p$ value } \\
\hline & Clustered & Unclustered & & \\
\hline Male sex & $40(56.3)$ & $37(63.8)$ & $0.73[0.34-1.58]$ & 0.40 \\
\hline Low incomes $(<465 €)$ & $21(29.6)$ & $14(24.1)$ & $2.03[0.73-5.68]$ & 0.13 \\
\hline Alcohol abuse ${ }^{a}$ & $15(21.1)$ & $12(20.7)$ & $0.73[0.25-2.15]$ & 0.50 \\
\hline Pulmonary localization of TB & $64(90.1)$ & $50(86.2)$ & $1.46[0.44-4.87]$ & 0.50 \\
\hline Age $<60$ years & $61(85.9)$ & $42(72.4)$ & $2.32[0.89-6.16]$ & 0.06 \\
\hline HIV positive & $16(22.5)$ & $9(15.5)$ & $1.41[0.51-3.96]$ & 0.50 \\
\hline Foreign born & $36(50.7)$ & $30(51.7)$ & $0.96[0.48-1.92]$ & 0.90 \\
\hline Underlying conditions ${ }^{b}$ & $30(42.3)$ & $28(48.3)$ & $0.78[0.37-1.67]$ & 0.50 \\
\hline Previous medical problems ${ }^{c}$ & $16(22.5)$ & $19(32.8)$ & $0.78[0.25-2.41]$ & 0.60 \\
\hline Diagnosis delay ${ }^{d}>26.5 \mathrm{j}$ & $44(62.0)$ & $43(74.1)$ & $0.57[0.25-1.29]$ & 0.14 \\
\hline Hospitalization & 18 (25.4) & $10(17.2)$ & $1.80[0.64-5.13]$ & 0.20 \\
\hline
\end{tabular}

a patients drinking more than 4 glasses of alcoholic beverages per day.

${ }^{b}$ homeless or living in shelters.

c other than preliminary tuberculosis.

${ }^{d}$ median delay between the first medical contact for tuberculosis symptoms and clinical suspicion of tuberculosis.

remain highly endemic [1]. This assumption is corroborated by the fact that the proportion of extrapulmonary TB increased in Guadeloupe from $11.6 \%$ in $1999-2005$ to $15.6 \%$ in $2006-2011$ (Table 5). In our study, foreignborn patients were more likely to be TB/HIV co-infected and also showed a higher proportion of extra pulmonary disease. These observations are likely not independent, although stratified analysis was not performed to be conclusive.

Regarding geographical mapping of TB cases, 5 out of 6 cities sharing $60 \%$ of TB burden in our study were characterized by higher population densities than the mean reported for Guadeloupe, and 3 out of 6 were also characterized by a higher proportion of underprivileged populations (more than $12.6 \%[28,29]$ ). Furthermore, TB patients in our study were characterized by a very high rate of unemployment (70.7\%; Table 1) and a below average income close to the official limit of poverty in France (monthly income of 824 EUR vs. 812 EUR/month in 2001; [29,30]).

Our results also provided with a first insight into the management of TB in Guadeloupe, and revealed that 38/107 (35.5\%) of patients for which information was available, consulted more than one physician before being diagnosed for TB. Interestingly, the management of patients improved in the period 2006-2011 [23] with a median delay of 55 days

Table 5 Evolution of epidemiological and clinical data concerning locally born and foreign born populations of TB patients in Guadeloupe between 1999-2005 (this study) and 2006-2011 (Cadelis et al., 2012 [23])

\begin{tabular}{|c|c|c|c|c|c|c|c|c|c|}
\hline \multirow[t]{2}{*}{ Parameters studied } & \multicolumn{3}{|c|}{ Total population of patients } & \multicolumn{3}{|c|}{ Foreign born } & \multicolumn{3}{|c|}{ Locally born } \\
\hline & $\begin{array}{c}1999-2005 \\
(n=129)\end{array}$ & $\begin{array}{c}2006-2011 \\
(n=128)\end{array}$ & $p$ & $\begin{array}{c}1999-2005 \\
(n=66)\end{array}$ & $\begin{array}{c}2006-2011 \\
(n=49)\end{array}$ & $p$ & $\begin{array}{c}1999-2005 \\
(n=63)\end{array}$ & $\begin{array}{c}2006-2011 \\
(n=79)\end{array}$ & $p$ \\
\hline Foreign born & $66(51.2)$ & 49 (38.3) & $<0.05$ & NA & NA & & & & \\
\hline Male & $77(59.7)$ & $80(62.5)$ & NS & $31(47.0)$ & $24(49.0)$ & NS & $42(66.7)$ & $56(70.9)$ & NS \\
\hline Prior history of active TB & $13(12.6)^{(a)}$ & $25(19.5)$ & NS & $4(7.0)^{(9)}$ & $8(16.3)$ & NS & 9 (19.6) $^{(\mathrm{l})}$ & $17(21.5)$ & NS \\
\hline Extrapulmonary TB & $15(11.7)$ & $20(15.6)$ & NS & $12(18.2)$ & $12(24.5)$ & NS & $3(4.8)$ & $8(10.1)$ & NS \\
\hline $\mathrm{HIV+}$ & $25(24.5)^{(b)}$ & $34(26.6)$ & NS & $21(38.2)^{(h)}$ & $23(46.9)$ & NS & $4(8.5)^{(m)}$ & $11(13.9)$ & NS \\
\hline Lost of sight & $33(29.2)^{(c)}$ & $8(6.3)$ & $<0.001$ & $13(23.2)^{(i)}$ & $1(2.0)$ & $<0.01$ & $20(35.1)^{(n)}$ & $7(8.9)$ & $<0.001$ \\
\hline Excessive alcohol user & $27(28.1)^{(d)}$ & $22(17.2)$ & 0.05 & $8(14.5)^{(h)}$ & $3(6.1)$ & NS & $19(46.3)^{(0)}$ & $19(24.1)$ & $<0.025$ \\
\hline Smoker & $19(20)^{(e)}$ & $30(23.4)$ & NS & $9(16.7)^{(j)}$ & $7(14.3)$ & NS & $10(24.4)^{(0)}$ & $23(29.1)$ & NS \\
\hline Drug user & $12(12.9)^{(f)}$ & $6(4.7)$ & $<0.05$ & $2(3.9)^{(k)}$ & $1(2.0)$ & NS & $10(24.4)^{(0)}$ & $5(6.3)$ & $<0.01$ \\
\hline
\end{tabular}

- Abbreviations: NA Not applicable.

- For Total population of patients: Information available for (a) 103/129 cases, (b) 102/129 cases, (c) 113/129 cases, (d) 96/129 cases,. (e) $95 / 129$ cases, (f) 93/129 cases

- For foreign-born patients: information available for (g) 57/66 cases, (h) 55/66 cases, (i) 56/66 cases, (j) 54/66 cases, (k) 52/66 cases.

- For French-born patients: information available for (I) 46/63 cases, (m) 47/63 cases, (n) 57/63 cases, (o) 41/63 cases. 
between the $1^{\text {st }}$ symptoms and clinical suspicion of TB instead of 74.5 days in 1999-2005; as well as the delay for clinical suspicion of TB after a $1^{\text {st }}$ medical consultation (18 days vs. 26.5 days). Comparison of foreign-born vs. French patients did not reveal significant differences in access to healthcare. Regarding treatment outcome, only $55.8 \%$ of patients were cured in our study since $15.0 \%$ of them deceased, and $29.2 \%$ were lost to follow up. These relatively mediocre TB management indicators as compared to Europe (74\% treatment success rate, $7 \%$ deceased, $12 \%$ lost to follow up; [31]), may indirectly be linked to the lack of awareness among the patient population in Guadeloupe, which is characterized by poor living conditions underlined earlier.

As far as feasibility of molecular typing in a prospective study is concerned, our results demonstrated that PCRbased spoligotyping not only correctly identified potential "outbreak" strains, but also allowed a fine characterization of the phylogeographical specificity of certain clones, e.g., SIT14/X3, SIT103/H1, and SIT1087/T1 (Table 2). The $2^{\text {nd }}$ line genotyping using 5-loci VNTRs allowed reducing the overestimation of clustering by spoligotyping [32]. However, it was apparently not enough discriminatory since 12-loci MIRUs performed retrospectively allowed to reduce both the clustering and recent transmission rates (Table 3). This observation argues for the use of spoligotyping with extended MIRU typing formats. In our study, mixed clusters involving both foreign-born and French patients concerned $11 / 18$ or $61 \%$ of clusters by spoligotyping and 5-loci VNTRs; however after retrospective 12-loci MIRU typing their number was reduced to 5 mixed clusters containing a total of 18 cases. Thus the suggested minimal requirement based on our study is 12-loci MIRUs, although the optimal format for molecular epidemiological investigations today is a new 15loci format $[33,34]$. Nonetheless, seeing the very low recent transmission rates found in our study, the future investigations should be extended to the sister island of Martinique, as well as French Guiana - since important migratory flows and exchanges exist between Guadeloupe and the 2 other French departments of the Americas. This might help detect both migratory flows, as well as direct and casual contacts, leading to the ongoing TB epidemic.

Last but not least, thanks to the comparison with an updated SITVIT2 database, we were able to conclude on the phylogeographical specificity of the circulating $M$. tuberculosis clones in Guadeloupe and surrounding regions. Most of this data commented earlier in the text clearly shows the predominance of evolutionary recent Euro-American group of isolates $[16,17]$ in our study. However, LAM, Haarlem and $\mathrm{T}$ lineages predominated in Guadeloupe, while the $\mathrm{X}$ lineage strains of suspected Anglo-Saxon descent $[16,17,35]$ were present to a smaller extent. Thus the bulk of TB transmission in Guadeloupe may be attributed to TB lineages shared with neighboring areas in the Caribbean and South and Central America [21,36]. Nonetheless, we further identified some clones such as SIT14/X3, SIT103/H1, and SIT1087/T1 (Table 2), which are highly specific for Guadeloupe. We now hope to extend a detailed molecular epidemiological study on the M. tuberculosis isolates from the 3 French departments isolated in 2006-2012 so as to see the evolution of above mentioned genotypes in time and space. Ultimate comparison of clusters retained after 12and 15-loci MIRUs should be done using 24-loci MIRUVNTRs [34] followed by the whole genome sequencing [37] of specific clones, in order to shed light on epidemiological and phylogenetical links between strains involved in active transmission, as well as to quantify how much $M$. tuberculosis isolates vary at the genomic level between epidemiologically linked patient clusters [38].

\section{Conclusions}

The present prospective genotyping study aimed to investigate TB transmission during a 7 year period in Guadeloupe, as well as to study the access to health care and follow-up of the TB patients diagnosed. The results obtained underline that the ongoing TB transmission in this insular, low TB-incidence setting of Guadeloupe was characterized by: (i) a significant proportion of imported cases of the disease from neighboring islands; (ii) a significantly higher $\mathrm{TB} /$ HIV coinfection among foreign-born cases; and, (iii) a higher proportion of cases affecting older age-group among French patients due to reactivation. Last but not least, this study also emphasized the need for universal typing using spoligotyping and 15-loci MIRUs in future prospective studies in Guadeloupe.

\section{Additional file}

Additional file 1: Table S1: Description of 57 spoligotype patterns from 129 M. tuberculosis clinical isolates in Guadeloupe, followed by a comparison with the SITVIT2 database (interrogation made on April 25th 2013)

\section{Competing interests}

The authors declare that they have no competing interests.

\section{Author's contributions}

Under a tripartite collaborative agreement, NR, MT, PC participated in the design and follow-up of the study. NR supervised the handling of pathological specimen, M. tuberculosis identification, drug-susceptibility testing, and genotyping of the strains. AA and ML collected epidemiological data; SF and SC interpreted the data; and SF performed statistical analysis. SF, SC, NR wrote the initial institutional report in French (http://www.pasteurguadeloupe.fr/tb/projects/tuberculose.pdf). JM performed retrospective molecular typing using 12-loci MIRUs and performed SITVIT2 database analysis. NR, SF, JM wrote the present manuscript All authors read and approved the final manuscript.

\section{Acknowledgements}

We sincerely thank A. Blateau (CIRE Antilles-Guyane-InVS) for helping with the elaboration of the protocol, and to J.L. Chappert, P. Quenel, D. Antoine and B. Decludt (CIRE Antilles-Guyane-InVS) for their constructive criticism throughout this investigation. We are grateful to V. Cornely (Observatoire 
Régional de la Santé de Guadeloupe) for helping with data analysis, and to C. Sola, I. Filliol and K. Brudey (Institut Pasteur de Guadeloupe) for various aspects concerning M. tuberculosis genotyping, and to T. Zozio, V. Hill, and D. Couvin (Institut Pasteur de Guadeloupe) for SITVIT2 database analysis. We are highly indebted to all individuals who helped during the course of this study, particularly colleagues from different hospital services in Guadeloupe: J.-M. Perez, M. Nicolas (Bacteriology), D. Caparoce, G. Cadelis (Pulmonary Medicine), I. Lamaury, M-T. Sow (Infectious Diseases), at the university hospital of Pointe-a-Pitre/Abymes; as well as other colleagues in other local hospitals or dispensaries situated in Pointe-à-Pitre, Basse-Terre, Marie-Galante, and Saint-Martin.

\section{Author details}

'Observatoire Régional de la Santé de la Guadeloupe, Basse-Terre, Guadeloupe, France. ${ }^{2}$ WHO Supranational TB Reference Laboratory, Institut Pasteur de la Guadeloupe, Abymes, Guadeloupe, France. ${ }^{3}$ Direction des Actions de Solidarité Départementale, Conseil Général de la Guadeloupe, Basse-Terre, Guadeloupe, France. ${ }^{4}$ CIRE Antilles-Guyane -InVS, Gourbeyre, Guadeloupe, France. ${ }^{5} \mathrm{CIRE}$ Antilles-Guyane -InVS, Fort de France, Martinique, France.

Received: 29 April 2013 Accepted: 17 July 2013

Published: 2 August 2013

\section{References}

1. World Health Organization: Global tuberculosis report 2012. Geneva, Switzerland: WHO; 2012. http://apps.who.int/iris/bitstream/10665/75938/1/ 9789241564502_eng.pdf.

2. Stop TB: Partnership: The Global Plan to Stop TB, 2006-2015. Actions for life: towards a world free of tuberculosis. Int I Tuberc Lung Dis 2006, 10:240-241.

3. Small P, Behr M: Molecular fingerprinting of Mycobacterium tuberculosis: how can it help the clinician? Clin Infect Dis 1997, 25:806-810.

4. Alland D, Kalkut G, Moss A, McAdam R, Hahn JA, Bosworth W, Drucker E, Bloom BR: Transmission of tuberculosis in New York City. An analysis by DNA fingerprinting and conventional epidemiologic methods. N Engl J Med 1994, 330:1710-1716

5. Small PM, Hopewell PC, Singh SP, Paz A, Parsonnet J, Ruston DC, Schecter GF, Daley CL, Schoolnik GK: The epidemiology of tuberculosis in San Francisco. A population-based study using conventional and molecular methods. N Engl J Med 1994, 330:1703-1709.

6. Kamerbeek J, Schouls L, Kolk A, van Agterveld M, van Soolingen D, Kuijper S, Bunschoten A, Molhuizen H, Shaw R, Goyal M, van Embden J: Simultaneous detection and strain differentiation of Mycobacterium tuberculosis for diagnosis and epidemiology. J Clin Microbiol 1997, 35:907-914.

7. Frothingham R, Meeker-O'Connell WA: Genetic diversity in the Mycobacterium tuberculosis complex based on variable numbers of tandem DNA repeats. Microbiology 1998, 144:1189-1196.

8. Sola C, Horgen L, Goh KS, Rastogi N: Molecular fingerprinting of Mycobacterium tuberculosis on a Caribbean island with IS6110 and DRr probes. J Clin Microbiol 1997, 35:843-846.

9. Sola C, Horgen L, Maïsetti J, Devallois A, Goh KS, Rastogi N: Spoligotyping followed by double-repetitive-element PCR as rapid alternative to IS6110 fingerprinting for epidemiological studies of tuberculosis. J Clin Microbiol 1998, 36:1122-1124

10. Horgen L, Sola C, Devallois A, Goh KS, Rastogi N: Follow up of Mycobacterium tuberculosis transmission in the French West Indies by IS6110-DNA fingerprinting and DR-based spoligotyping. FEMS Immunol Med Microbiol 1998, 21:203-212.

11. Filliol I, Ferdinand S, Negroni L, Sola C, Rastogi N: Molecular typing of Mycobacterium tuberculosis based on variable number of tandem DNA repeats used alone and in association with spoligotyping. J Clin Microbiol 2000, 38:2520-2524.

12. van Soolingen D, de Haas PE, Hermans PW, van Embden JD: DNA fingerprinting of Mycobacterium tuberculosis. Methods Enzymol 1994, 235:196-205.

13. Supply P, Lesjean S, Savine E, Kremer K, van Soolingen D, Locht C Automated high-throughput genotyping for study of global epidemiology of Mycobacterium tuberculosis based on mycobacterial interspersed repetitive units. J Clin Microbiol 2001, 39:3563-3571.
14. Supply P, Mazars E, Lesjean S, Vincent V, Gicquel B, Locht C: Variable human minisatellite-like regions in the Mycobacterium tuberculosis genome. Mol Microbiol 2000, 36:762-771.

15. Millet J, Miyagi-Shiohira C, Yamane N, Sola C, Rastogi N: Assessment of mycobacterial interspersed repetitive unit-QUB markers to further discriminate the Beijing genotype in a population-based study of the genetic diversity of Mycobacterium tuberculosis clinical isolates from Okinawa, Ryukyu Islands, Japan. J Clin Microbiol 2007, 45:3606-3615

16. Brudey K, et al: Mycobacterium tuberculosis complex genetic diversity: mining the fourth international spoligotyping database (SpolDB4) for classification, population genetics and epidemiology. BMC Microbiol 2006, 6:23.

17. Demay C, Liens B, Burguiere T, Hill V, Couvin D, Millet J, Mokrousov I, Sola C, Zozio T, Rastogi N: SITVITWEB - a publicly available international multimarker database for studying Mycobacterium tuberculosis genetic diversity and molecular epidemiology. Infect Genet Evol 2012, 12:755-766.

18. Che D, Bitar D: Les cas de tuberculose déclarés en France en 2004. Bull Epidemiol Hebdo 2006, 18:121-125.

19. Khue PM, Truffot-Pernot C, Texier-Maugein J, Jarlier V, Robert J: A 10-year prospective surveillance of Mycobacterium tuberculosis drug resistance in France 1995-2004. Eur Respir J 2007, 3:937-944.

20. Antoine $D$, Che D: Epidemiology of tuberculosis in France in 2005 Bull Epidemiol Hebdo 2007, 11:85-92.

21. Brudey K, Filliol I, Ferdinand S, Guernier V, Duval P, Maubert P, Sola S, Rastogi N: Long-term population-based genotyping study of Mycobacterium tuberculosis complex isolates in the French Departments of the Americas. J Clin Microbiol 2006, 44:183-191.

22. World Health Organization (WHO): Global Tuberculosis Control - Surveillance, Planning, Financing. Geneva, Switzerland: WHO Library Cataloguing-in-Publication Data (WHO/HTM/TB/2007.376), World Health Organization; 2007.

23. Cadelis G, Rossigneux E, Millet J, Rastogi N: Comparative epidemiological study of the tuberculosis - migrant and native subjects in Guadeloupe from 2006 to 2011. Rev Mal Respir 2012, 29:858-870.

24. Moriane E, Pitot S: Atlas des populations immigrées en Guadeloupe. Insee; 2006. www.insee.fr/fr/insee_regions/guadeloupe/themes/etudes_detaillees/ atlasimmigres/atlas_immigres_ga.pdf.

25. Secrétariat Général du Comité Interministériel de Contrôle de I'Immigration: Rapport au Parlement - Les orientations de la politique de l'immigration et de l'intégration. 2011. www.ladocumentationfrancaise.fr/ docfra/rapport_telechargement/var/storage/rapports-publics/124000036/ 0000.pdf.

26. Cazein F, Le Vu S, Pillonel J, Le Strat Y, Couturier S, Basselier B, Lot F, Semaille C: Dépistage de l'infection par le VIH en France, 2003-2009. Bull Epidemiol Hebd 2010, 45-46:451-454.

27. Agence nationale de recherches sur le sida et les hépatites virales - Observatoire régional de santé d'lle-de-France: Les connaissances, attitudes, croyances et comportements face au VIH/sida aux Antilles et en Guyane en 2004. ANRS lle-deFrance; 2006. mww.ors-idf.org/dmdocuments/KABPDFARapport.pdf

28. Insee: Tableaux économiques Régionaux de Guadeloupe; 2007. http://www. insee.fr/fr/themes/document.asp?reg_id=26\&ref_id=17976.

29. Insee: Les inégalités aux Antilles Guyane : dix ans d'évolution; 2009. http:// www.insee.fr/fr/insee_regions/guadeloupe/themes/etudes_detaillees/ inegalitesAG/inegalitesAG.pdf.

30. Insee: Taux de chômage en France; 2012. http://www.insee.fr/fr/themes/inforapide.asp?id=14

31. European Tuberculosis Surveillance Network. www.ecdc.europa.eu/en/ publications/Publications/SUR_TB_EuroTB_Annual_report_2005_Full_report. pdf.

32. Sola C, Filliol I, Legrand E, Lesjean S, Locht C, Supply P, Rastogi N: Genotyping of the Mycobacterium tuberculosis complex using MIRUs: association with VNTR and spoligotyping for molecular epidemiology and evolutionary genetics. Infect Genet Evol 2003, 3:125-133.

33. Supply P, Allix C, Lesjean S, Cardoso-Oelemann M, Rüsch-Gerdes S, Willery E, Savine E, de Haas P, van Deutekom H, Roring S, Bifani P, Kurepina N, Kreiswirth B, Sola C, Rastogi N, Vatin V, Gutierrez MC, Fauville M, Niemann S, Skuce R, Kremer K, Locht C, van Soolingen D: Proposal for standardization of optimized mycobacterial interspersed repetitive unit-variable-number tandem repeat typing of Mycobacterium tuberculosis. J Clin Microbiol 2006, 44:4498-4510.

34. Allix-Béguec C, Fauville-Dufaux M, Supply P: Three-year populationbased evaluation of standardized mycobacterial interspersed 
repetitive-unit-variable-number tandem-repeat typing of Mycobacterium tuberculosis. J Clin Microbiol 2008, 46:1398-1406.

35. Rastogi N, Sola C: Chapter 2 - Molecular evolution of the Mycobacterium tuberculosis complex. In Tuberculosis 2007: from basic science to patient care. Edited by Palomino JC, Leao S, Ritacco V. 2007:53-91. Amedeo Online Textbooks. http://eglobalmed.com/opt/AmedeoLiteratureGuide/www. tuberculosistextbook.com/tuberculosis2007.pdf.

36. Millet J, Baboolal S, Akpaka PE, Ramoutar D, Rastogi N: Phylogeographical and molecular characterization of an emerging Mycobacterium tuberculosis clone in Trinidad and Tobago. Infect Genet Evol 2009, 9:1336-1344.

37. Walker TM, Ip CL, Harrell RH, Evans JT, Kapatai G, Dedicoat MJ, Eyre DW, Wilson DJ, Hawkey PM, Crook DW, Parkhill J, Harris D, Walker AS, Bowden R, Monk P, Smith EG, Peto TE: Whole-genome sequencing to delineate Mycobacterium tuberculosis outbreaks: a retrospective observational study. Lancet Infect Dis 2013, 13(2):137-46. 10.1016/S1473-3099(12)70277-3. Epub 2012 Nov 15

38. Rastogi N: F1000Prime Recommendation of [Walker TM et al. Lancet Infect Dis 2013, 13(2):137-46. In F1000Prime, 25 Feb 2013; doi: 10.3410/ f.717967420.793471198. F1000Prime.com/717967420\#eval793471198.

doi:10.1186/1471-2334-13-364

Cite this article as: Ferdinand et al:: Use of genotyping based clustering to quantify recent tuberculosis transmission in Guadeloupe during a seven years period: analysis of risk factors and access to health care. BMC Infectious Diseases 2013 13:364.

\section{Submit your next manuscript to BioMed Central and take full advantage of:}

- Convenient online submission

- Thorough peer review

- No space constraints or color figure charges

- Immediate publication on acceptance

- Inclusion in PubMed, CAS, Scopus and Google Scholar

- Research which is freely available for redistribution 